\title{
Union Therapy-An Urgent Need to Health Care for Covid and Future Threats
}

\author{
Kanishk Kala*, Rupinder Kaur Sodhi \\ Department of Pharmacology, Chandigarh College of Pharmacy, I. K. Gujral Punjab Technical University, Jalandhar, \\ Punjab, INDIA.
}

Received: 01 May 2020

Accepted: 18 June 2020

*Correspondence to:

Ms. Kanishk Kala,

M.Pharm, Research Scholar, Department of Pharmacology, Chandigarh College of Pharmacy, Chandigarh Group of Colleges,

I. K. Gujral Punjab Technical University, Jalandhar-140307, Punjab, INDIA. Email:kanishk.kala@gmail.com Copyright: (C) the author(s),publisher and licensee Indian Academy of Pharmacists. This is an open-access article distributed under the terms of the Creative Commons Attribution Non-Commercial License, which permits unrestricted non-commercial use, distribution, and reproduction in any medium, provided the original work is properly cited.

\begin{abstract}
Human suffering through infections is inevitable. History has witnessed drastic negative impacts of infectious plagues which were primarily managed through prayers and latter through medicines. In spite of high technology at present COVID-19 and other resistant infections and diseases still pose a threat to global health and still is unchecked. Thus to combat it a modality Union therapy is conceptualized which synergistically uses the past and present medical techniques to cope up the COVID. It tries to merge the positive effects of supernatural medicine with modern medicine to make therapy comprehensive complete in all aspects. This effort would help to cope up new emerging diseases like COVID and in cases of palliative care where psychological aspects and the patient's religious and spiritual needs play a role. Overall it will help to frame a bridge between past and present treatment modalities by scientifically assessing and merging the objective similarities in them. It will help to foster new areas and make therapy acceptable and accessible to a wide range of global population.
\end{abstract}

Key words: Union Therapy, COVID-19, Holistic Medicine, Integrative medicine, Mytho scientific.

\section{BACKGROUND}

In past religion and medicine were linked. The ancient medicine had a supernatural element embedded in it which was usually a deity or supernatural spirit of ancestors the common link between was that they were regarded as sacred as per their beliefs and culture..$^{[1,2]}$

\section{INTRODUCTION}

First and foremost forms of treatment were prayers offered to the deities in temples or places of worship. ${ }^{[3]}$ The other forms of treatment included rituals, ceremonies carried on specific timings encompassing a time or kala element in theme which was linked with the alignment of nature and its associated events. In addition of time element a standard procedure was also linked which took form of a ritual of ceremony with due course of time. ${ }^{[4]}$

However studies conducted in modern time also showed that up to $33 \%$ and $77 \%$ of patients insist on fulfillment of their spiritual needs especially in palliative care scenario where spirituality and religion holds a prominent place. Religion can be addressed as set of beliefs and practices shared by a community however spirituality is referred as a person's existential relationship with almighty Spirituality is a way of life along with the core belief. It is not restricted within a frame of a religion rather it is independent and could be attained through positive interaction with nature and surroundings. Though both terms are perceived different but the fundamental of the two is the same thus both are linked through a belief in almighty and to live in positive frame as per core beliefs. ${ }^{[5]}$ In modern science perspective studies reveal that spirituality is linked with improvement in depression cognitive impairment pain and quality of life hence spirituality counseling in all medical conditions preferably in chronic medical illnesses and terminal conditions or un treatable illness must be done to make therapy complete in all aspects. Spirituality inclusion in treatment has shown improvements in cardiovascular, cerebrovascular, pulmonary diseases and dealing with negative impacts of treatment outcome. Hence the inclusion of religion and belief in treatment is a tool to make therapy comprehensive acceptable accessible and to invoke faith acceptability compatibility and adherence in patient towards therapy. ${ }^{[6]}$

\section{ASTROLOGY AS LINK BETWEEN SCIENTIFIC AND SUPERNATURAL MEDICINE}

Astrology is influence of planets on humans. Started in Mesopotamia by Sumerians. Babolyians also have identified 7 stars in their text Mu lapin and have deified and offered them prayers and rituals. These seven stars are still present in horoscopes. Rituals including sacrifices were conducted during 18000 BCE for stars. Astrological knowledge was transferred to Egypt where it went amendments of medical orientations leading to a new form known as hermentic astrology dedicated to deity Hermes. In hermetic astrology heavenly phenomena and body were assumed linked and collectively known as Moleothesy providing basis of a holistic medical orientation. It also shares the view of positive impacts of heavenly objects like Moon, Sun, Mercury Venus, Mars, Jupiter and Saturn on drugs as well as the treatment which is referred as Astrobotany. ${ }^{[7]}$ The same thing is practiced in ayurveda also where the drugs are affected by nature and specific time intervals known as nakshatra are designated for a medicine processing. ${ }^{[8]}$ Further this knowledge was transmitted to Greeks who latter improvised it and formed 12 zodiacs. Ancient scriptures also stress the influence of heavenly objects on objects on earth. Even Galen and Hippocrates the pioneers of modern medicine supported the view of impact of astronomy and astrology on medicine. ${ }^{[7]}$ 


\section{Kala and Sodhi.: Merging Supernatural to Scientific Making Healthcare Comprehensively Holistic}

In Indian context astrology constitutes of a horoscope which depicts position of planets which rule the past, present and future of an individual. The chart has 12 houses of which first are lagna and rest are studied linked with the first. These twelve houses are designated to different parts of the body thus have a role in health. The astrology can help in different aspects of health. Harmful planets could be managed through astrological remedies. For good health deities like Sun, Moon and eighth house are checked. In addition remedies are followed to prevent any negative outcome. Even illness in coming time can also be assessed by astrologer by using techniques like Vimsottsrdasa (which involves a cycle of 120 years) and Yogindasa (involving a cycle of 36 years). An astrologer can diagnose disease severity, outcome and can even provide remedies to diseases not managed by modern science from horoscope. ${ }^{[9]}$ This phenomena should be accessed for clinical evidence and latter recorded in a database that could latter filter duplicate and similar intervention hence could help to bridge supernatural to scientific evidence as an intervention of union therapy thus framing a background for mythoscientific health model which could be comprehensively holistic. Similarly, the astrological aspect of medicine is also practiced in Ayurveda where Tridosha are linked with the astrological fractions. The Chinese Medical System referred as TCM also shares link with Ayurveda. Here it is referred as horoscope men and the disease along with its treatment done through the horoscope. It is striking to find that the Kampo medicine has fundamental links with TCM. This supports the fact that holistic nature of therapy is based on fact that supports the interconnectedness of person with nature and in this the common link of astrology as a part of medicine plays a vital role across different cultures. ${ }^{[10]}$ Astrology is also related to tantra which is referred as a sect in Indian philosophy pays due attention to time and astronomy which is known as kala a name of time of diety Shiva. Tantra is referred as set of organized procedures for a desired outcome. In past when the belief and dependency on supernatural was high. ${ }^{[4]}$
In modern times, the relation of the sun and moon to disease and treatment is not restricted to religion or to traditional medicine rather it has a proven scientific ground as renal endocrinology is linked to these two heavenly bodies. Sun is source of Vitamin D fluctuations of which cause many diseases. The production of Vitamin D also requires a healthy and functional kidney hence both organ and sun light are linked for good health. However moon affects behavior of a person and is linked with psychological disorders studies have shown that moon is a enhancing factor for diseases like in seizures, deregulation CVS disorders behavior changes menstrual changes and full term deliveries. ${ }^{[1]}$ Scientifically moon affects the hormone melatonin which plays a role in oxidative stress, inflammation, proteinuria, and renal damage progression in animal studies. In addition studies show that renal colic follows lunar cycle pattern high incidence on full moon day and less on other days. ${ }^{[1]}$

Thus this rational scientific evidence shows a link between effects of heavenly bodies and natural objects in normal physiology of a human being hence forcing us to think health in holistic context and to access the supernatural elements and their effects on scientific basis and after assessment framing interventions to frame a universal treatment modality which could merge this supernatural belief phenomena with modern treatment regimen to maximize the therapeutic effect improve adherence faith and acceptance and accessibility of the treatment on global scale. ${ }^{12-15}$ A diagram for merging supernatural to science ids depicted as follows-

Every disease irrespective of origin has physical and psychological aspects hence a portion of psychological aspect of therapy is to be included in every disease management to ensure a comprehensive and complete cure viewing this the aspects of psychotherapy comes in operation in every disease management which in modern science is restricted only to specific psychiatric diseases. Treating or strengthen psychology towards a positive side would aid

\begin{tabular}{|c|c|c|c|c|c|}
\hline \multicolumn{5}{|c|}{ UNION THERAPY- Merging Supernatural to Scientific. ${ }^{[1-15]}$} & \\
\hline Elements & Basis & Target & Concept & Need & \\
\hline Belief & $\begin{array}{l}\text { Culture and customs } \\
\text { beliefs }\end{array}$ & $\begin{array}{l}\text { Psychological assessment } \\
\text { of patient }\end{array}$ & Faith in therapy & $\begin{array}{l}\text { Helps to frame treatment based } \\
\text { on beliefs will help in improving } \\
\text { adherence / acceptability. }\end{array}$ & $\begin{array}{l}\text { Filter and document } \\
\text { similar beliefs and } \\
\text { frame treatment plan } \\
\text { accordingly }\end{array}$ \\
\hline Supernatural identity & $\begin{array}{l}\text { Deity /supernatural } \\
\text { element linked with } \\
\text { faith nature/natural } \\
\text { phenomena or } \\
\text { astrology }\end{array}$ & $\begin{array}{l}\text { Positive psychological } \\
\text { support to patient based on } \\
\text { his inherent beliefs }\end{array}$ & $\begin{array}{l}\text { Ensure faith and } \\
\text { completeness of therapy } \\
\text { in patient due to almighty } \\
\text { intervention }\end{array}$ & $\begin{array}{l}\text { Access psychological, spiritual } \\
\text { or religious needs of patients } \\
\text { especially in palliative care } \\
\text { and frame treatment blended } \\
\text { with religious/belief needs to } \\
\text { make therapy acceptable and } \\
\text { effective. }\end{array}$ & $\begin{array}{l}\text { Filter similar beliefs and } \\
\text { to make uniformity in } \\
\text { the belief of patient and } \\
\text { increase compatibility } \\
\text { acceptance adherence } \\
\text { and faith of patient on } \\
\text { therapy }\end{array}$ \\
\hline Astrology in treatment & $\begin{array}{l}\text { Role of astrology in } \\
\text { framing treatment of } \\
\text { disease of patients }\end{array}$ & $\begin{array}{l}\text { Including various parameters } \\
\text { of disease management } \\
\text { and making therapy } \\
\text { comprehensively holistic i.e } \\
\text { union therapy }\end{array}$ & $\begin{array}{l}\text { Accessing or implementing } \\
\text { the advises given } \\
\text { astrologically for treatment }\end{array}$ & $\begin{array}{l}\text { Data base formulation, Data } \\
\text { filtering among views between } \\
\text { different cultures / intervention } \\
\text { or development of new } \\
\text { protocols }\end{array}$ & $\begin{array}{l}\text { Frame a astrological form } \\
\text { of remedial medicine } \\
\text { synchronized with the } \\
\text { medical precautions } \\
\text { and check it for clinical } \\
\text { evidence }\end{array}$ \\
\hline Tantra/mantra /amulets & $\begin{array}{l}\text { Positive effect in mind } \\
\text { and body link with } \\
\text { astrology faith and } \\
\text { religion }\end{array}$ & $\begin{array}{l}\text { Operation of higher order } \\
\text { of therapeutics used for } \\
\text { uncontrolled disease like } \\
\text { COVID - } 19 \text { merging scientific } \\
\text { basis of supernatural } \\
\text { procedure. }\end{array}$ & $\begin{array}{l}\text { Blending mantras as a part } \\
\text { of non-pharmacological } \\
\text { treatment form in the life } \\
\text { style modification }\end{array}$ & $\begin{array}{l}\text { Data filtering/ intervention } \\
\text { or development of new } \\
\text { protocols and testing myths } \\
\text { throughassessment of } \\
\text { outcomes though scientific } \\
\text { methods for clinical evidence } \\
\text { and development of new } \\
\text { comprehensive wing of } \\
\text { treatment }\end{array}$ & $\begin{array}{l}\text { Linking super natural age } \\
\text { old beliefs with modern } \\
\text { science and check it } \\
\text { for clinical evidence to } \\
\text { merge it with modern } \\
\text { science }\end{array}$ \\
\hline Pharmacological treatment & $\begin{array}{l}\text { Clinical management } \\
\text { of disease through } \\
\text { blending } \\
\text { With super }\end{array}$ & $\begin{array}{l}\text { Use of medical treatment } \\
\text { And life style/ non } \\
\text { pharmacological blending } \\
\text { with supernatural }\end{array}$ & $\begin{array}{l}\text { Disease management } \\
\text { Clinical blended with } \\
\text { supernatural }\end{array}$ & $\begin{array}{l}\text { Patient treatment / Management } \\
\text { blended with supernatural }\end{array}$ & $\begin{array}{l}\text { Framing clinical } \\
\text { treatment synchronized } \\
\text { with supernatural } \\
\text { beliefs to make therapy } \\
\text { comprehensive holistic } \\
\text { a mythoscentific health } \\
\text { model }\end{array}$ \\
\hline
\end{tabular}


in positive health outcomes. This involves the use of root cause analysis and elimination which means Nidana Parivarjana, cause elimination, Daivavyapasraya (divine seeking), Magico religious modalities like Mantrab (hymns), Manidharan (Precious Stones), Oushadam (Amulets), Mangalam (Propitiatory Rituals). Such practices were performed in almost every civilization including China, Egypt, Mesopotamia, Greek, Rome, America, Mayans Inca. ${ }^{[13,14]}$ Hence this indicates that to make modern health care complete in all aspects as per WHO which also advocates different vocations of health and not see it as merely absence of disease a new concept of union therapy is proposed which advocates every treatment modality having a positive effect and respect every treatment practice irrespective of origin. This concept respects every treatment modality having a positive outcome and compromises utilization of objective similarities of higher order therapeutics holistic approach, conceptual interactions and links between medicine systems religious cultural and individualistic traits to aid in treatment and improve adherence and outcome. This could be a tool in COVID -19 where modern science is not effective hence going back to roots and crosschecking ancient knowledge on modern clinical evidence could help us to develop a new modality to combat COVID-19 or any such future untreatable threat. ${ }^{15,16}$

\section{CONCLUSION}

Every culture has its own inherent beliefs which centers round a supernatural deity which makes the therapy complete. This supernatural element is not considered in modern science Though the beliefs shape spirituality and psychology of individual which have shown positive impacts in several studies. The deity is connected to nature which encompasses planets and heavenly bodies which forms the basis of astrology hence making it a link between supernatural and scientific science Studies show that it played role in ancient treatment. In addition every disease has a psychological aspect hence integrating the two in treatment would help to integrate psychological as well as religious or spiritual dimensions of therapy in scientific manner making therapy comprehensively complete which could make therapy accessible acceptable applicable in almost all clinical situations. ${ }^{[15,16]}$

\section{ACKNOWLEDGEMENTS}

Sincere thanks to my Father Dr. Shankar Kala and Guide Dr. Rupindrer Kaur Sodhi for their support.

\section{CONFLICT OF INTEREST}

The authors declare no conflict of interest.

\section{REFERENCES}

1. Hajar R. The Air of History Early Medicine to Galen (Part I). Heart Views. 2012;13(3):120-8.

2. Zuskin E, Lipozencic J, Cvetkovic JP, Mustajbegovic J, Schachter N, Pucic BM. et al. Ancient Medicine: A Review. Acta Dermatovenerol Croat. 2008;16(3):149-57.

3. Khan N. Evolution of Hospitals and its Management. AJMS. 2013;01(1):12-21.

4. Venkatraman A, Nandy R, Rao SS, Mehta DH, Viswanathan A, Jayasundar R. Tantra and modern neurosciences: Is there any correlation?. Neurol India. 2019;67(5):1188-93.

5. Abdulla A, Hossain M, Barla C. Toward Comprehensive Medicine: Listening to Spiritual and Religious Needs of Patients. Gerontology and Geriatric Medicine. 2019; 5:1-6.

6. Singh DM, Ajinkya S. Spirituality and religion in modern medicine. Indian J Psychol Med. 2012;34(4):399-402.

7. Saparmin NB. History of Astrology and Astronomy in Islamic Medicine. International Journal of Academic Research in Business and Social Sciences. 2019;9(9):282-96.

8. Deshmukh KS. Good collection and storage practices, an ayurvedic perspective. IJAAR. 2015;2(3):357.

9. Sharma BV. Prasad PVV, Narayana A. Contribution of Astrology In Medicine - A Review. Journal Ind Inst Hist Med. 2007;37:45-62.

10. Sen S, Chakraborty R. Revival, modernization and integration of Indian traditional herbal medicine in clinical practice: Importance, challenges and future Journal of Traditional and Complementary Medicine. 2017;7:234e244

11. Arampatzis S, Thalmann GN, Zimmermann H, Exadaktylos AK. Lunar tractive forces and renal stone incidence. Emergency Medicine International. 2011.

12. Kalra S, Bandgar T, Sahay M. The sun, the moon and renal endocrinology. Indian Journal of Endocrinology and Metabolism. 2012;16(2):156-7.

13. ReFaey, K, Clifton W, Quinones GC, Tripathi S, Quiñones A. Mysterious Civilizations: Is There a Connection between Medicine and Architecture in Ancient Egypt and Peru?. Cureus. 2019;11(4).

14. Behere PB, Das A, Yadav R, Behere AP. Ayurvedic concepts related to psychotherapy. Indian J Psychiatry. 2013;55(Suppl 2):S310-4.

15. Kala K, Sodhi RK, Jain UK. A review on union therapy: Denovo dimension towards health role in infection and resistance. J Pharm Sci Innov. 2019;8(1).

16. Kala K, Sodhi RK. Union Therapy: A Weapon against Covid 19. International Journal of Hospital Pharmacy. 2020;5:36.

Cite this article as: Kala K, Sodhi RK. Union Therapy-An Urgent Need to Health Care for Covid and Future Threats. J Pharm Pract Community Med. 2020;6(2):22-4. 